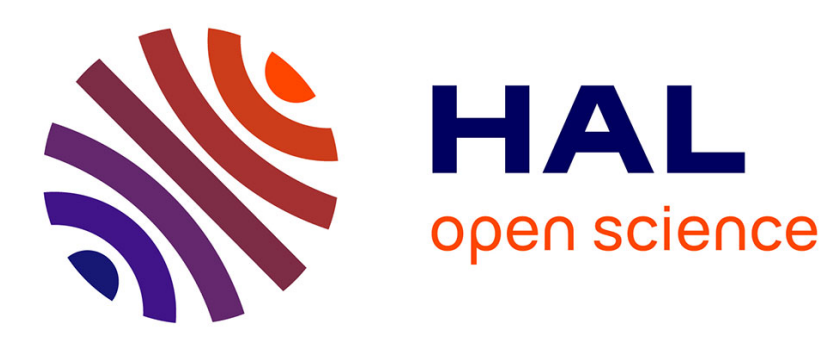

\title{
ASTRID. The Aarhus dual purpose storage ring for positive/negative ions and electrons \\ E. Uggerhøj
}

\section{To cite this version:}

E. Uggerhøj. ASTRID. The Aarhus dual purpose storage ring for positive/negative ions and electrons. Journal de Physique IV Proceedings, 1994, 04 (C9), pp.C9-349-C9-356. 10.1051/jp4:1994959 jpa00253522

\section{HAL Id: jpa-00253522 https://hal.science/jpa-00253522}

Submitted on 1 Jan 1994

HAL is a multi-disciplinary open access archive for the deposit and dissemination of scientific research documents, whether they are published or not. The documents may come from teaching and research institutions in France or abroad, or from public or private research centers.
L'archive ouverte pluridisciplinaire HAL, est destinée au dépôt et à la diffusion de documents scientifiques de niveau recherche, publiés ou non, émanant des établissements d'enseignement et de recherche français ou étrangers, des laboratoires publics ou privés. 


\title{
ASTRID. The Aarhus dual purpose storage ring for positive/negative ions and electrons
}

\author{
E. Uggerhøj
}

Institute for Synchrotron Radiation, Aarhus University, 8000 Aarhus C, Denmark

\begin{abstract}
The $(10.6 \times 10.6) \mathrm{m}^{2}$ storage ring in Aarhus is now operating both with ions (positive/negative) and with electrons $\left(E_{\max }=580 \mathrm{MeV}\right.$ ) for production of synchrotron radiation (SR). In the ion case more than 30 ions and clusters have been stored - lowest energy $5 \mathrm{keV}$. Equipment for laser- and electron-cooling is installed. Until now three SR-beamlines have been installed: one with a Zeiss plane grating monochromator (SX-700) and a complete UHVequipment for surface physics. The second one includes a new spherical grating monochromator (SGM) for atomic physics equipment. The third is dedicated to an imaging $x$-ray microscope. Thus, today ASTRID is the scene of a wide range of research using SR from infrared to $x$-rays and ions of many types. For the ion case an EBIS ion source for injection of multiply charged ions is under construction, together with a new detection facility for charge and mass detection of collision fragments. For SR a VUV undulator is under construction.
\end{abstract}

\section{Introduction}

The idea behind the Aarhus storage ring was to design a facility which could function both as a synchrotron radiation source (SR) in the XUV/VUV region and as a ring for ion storage. The ion storage was meant to be used for investigations of laser cooling and atomic collisions in flight, using the electron cooler as a target.

The storage ring was operational with ions in the spring 1990 and with electrons in April 1991. In the following, the storage ring and injectors will be presented, followed by a short description of the equipment for cooling and SR-experiments. Also the new ion sources and detection facilities will be described together with plans for an upgrading of ASTRID as a SR-source.

\section{The storage ring ASTRID}

In Fig. 1 is shown the underground laboratory housing: ASTRID, injectors and SR beamlines. Only the electron injector (a $100 \mathrm{MeV}$ microtron) is placed in a shielded room. The radiation level in the laboratory is only hazardous during electron injection, why the hall is evacuated during these few minutes. The minor shielding around the bending magnets means that large solid angles ( $\leq 50 \mathrm{mrad})$ of SR can be accepted by the monochromators.

ASTRID $[1,2]$ is quadratic with two $45^{\circ}$ bending magnets in each corner. The lattice configuration resembles that of LEAR, CERN. The four groups of quadrupoles enable two modes of focussing, namely: one with a four-fold symmetry and one with a two-fold sym- 
metry. In the latter, the dispersion function in two opposite straight sections can be varied continuously between 0 and $6 \mathrm{~m}$ without changing the working point. Lattice functions are summarized in Table 1 and plotted in Fig. 2. Here it can be seen that two straight sections are dispersion free. This is important for introducing insertion devices, cooling experiments and co-rotating ions with difference in velocity.

Two families of 8 sextuples are available for chromaticity corrections. These sextuples are surrounded by 8 vertical and 8 horizontal correction dipoles. On the main dipoles there are back-leg windings for a relative correction of the dipoles.

The rest-gas collisions is one of the limiting factors for the lifetime of stored ions, hence the vacuum system is designed for the $10^{-12}$ torr region. To obtain such low working pressure, the system must be baked to $300^{\circ} \mathrm{C}$ by a permanent bake-out installation. Clearing electrodes are installed to reduce ion trapping from rest gas.

\begin{tabular}{||l|l|}
\hline Magnetic rigidity & $1.87 \mathrm{Tm}$ \\
\hline Circumference & $40 \mathrm{~m}$ \\
\hline Hor., vert. tune & $2.29,2.73$ \\
\hline Hor., vert. chromaticity & $-3.4,-7.5$ \\
\hline Momentum compaction & 0.053 \\
\hline
\end{tabular}

Table 1: ASTRID parameters.

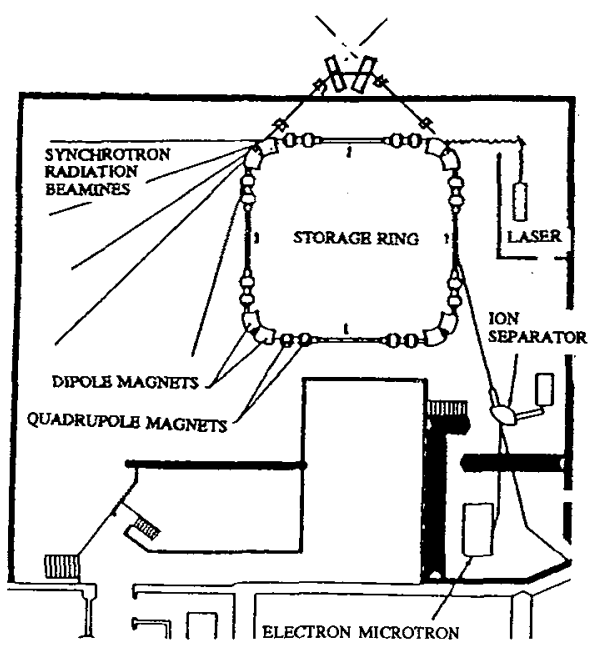

Figure 1: Layout of the ASTRID laboratory.

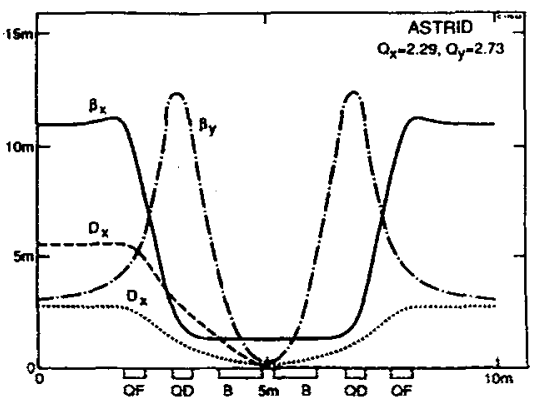

Figure 2: Lattice function of ASTRID.

For acceleration, two different RF-systems are used. In the ion case a ferrite-loaded cavity is available, which operates in the region of $(0.4-5) \mathrm{MHz}$, giving a maximum voltage of $2 \mathrm{kV}$. For electrons a copper-plated coaxial TEM cavity is used, operating at $104.9 \mathrm{MHz}$.

For injection, a common magnetic septum and a kicker (magnetic/electrostatic) is used. With this septum it is also possible to extract all electrons in the ring in one short pulse or part of them (the tail) during operation for SR. Such secondary electrons can be used to test new equipment for high-energy physics and astrophysics.

In all, the change over from ion storage to SR production only requires exchange of the RF/kicker unit - a 1-2 days operation; because of this easy exchange procedure the running schedule is now parted up in 10 weeks periods alternating between ion- and electron storage.

The beam diagnosties consist of 8 horizontal and vertical position pick-ups, scintillation screens, transverse and longitudinal Schottky pick-ups, beam current transformers, beam scrapers, and position-sensitive SR detectors. 
The control system is modelled after LEAR, and is based on a NORD main computer with PCs as consoles. The dynamics parameters are controlled by specially programmed function generator modules downloaded from the control computer.

\section{Injectors}

\section{a. The ion injector.}

A $200 \mathrm{kV}$ isotope separator with a very stable power supply (RMS $<1 \mathrm{~V}$ ) is used for ion injection. Three different types of ion sources can produce single and multiple charged ions of nearly all elements. A charge exchange cell is installed in the injection line to increase the current of negative ions. Differential pumping separates the high pressure $\left(10^{-2}\right.$ torr) in the ion source from the ultra high vacuum $\left(10^{-12}\right.$ torr) in the storage ring. A new injection

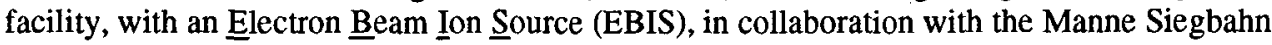
Laboratory, Stockholm, is under construction. Here, highly charged ions are produced with charge states up to around 20 . The ionization is performed by an electron beam which is focussed and injected into a solenoidal magnetic field, where the electrons are compressed to a high current density. Atoms injected into the solenoid will be ionized and radially trapped. By increasing the potential of the central drift tube, the ions are extracted into the injection line.

\section{b. The electron injector.}

A 100 MV race-track microtron (RTM), developed by M. Eriksson, Lund, Sweden, has been built (see Ref. 3 for details). The RTM parameters are given in Table 2.

\begin{tabular}{||l|l||}
\hline \hline Injection energy & $70 \mathrm{keV}$ \\
\hline Resonant energy gain & $5.3 \mathrm{MeV}$ \\
\hline Number of turns & 19 \\
\hline Final electron energy & $100 \mathrm{MeV}$ \\
\hline Energy spread & $100 \mathrm{keV}$ \\
\hline Pulse current & $10-20 \mathrm{~mA}$ \\
\hline Pulse length & $1 \mu \mathrm{s}$ \\
\hline Repetition frequency & $10 \mathrm{~Hz}$ \\
\hline Emittance & $0.1 \mathrm{~mm} \mathrm{mrad}$ \\
\hline RF frequency & $2998.6 \mathrm{MHz}$ \\
\hline Dipole field & $1.15 \mathrm{~T}$ \\
\hline
\end{tabular}

Table 2: RTM parameters.

\section{Beam size - cooling}

As mentioned above, the ASTRID lattice is dispersion free in opposite straight sections (Fig. 2). For a SR source the beam size in the dipoles should be very small in order to obtain a good emittance and dispersion-free in straight section for insertion devices. From Fig. 3 is seen that the ASTRID lattice fulfills these requirements.

In the case of ion storage, two different cooling schemes are installed, i.e. laser cooling and electron cooling. The basic idea in laser cooling is shown in Fig. 4. In one of 


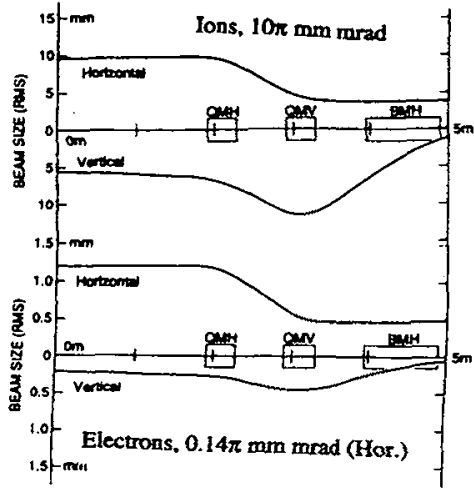

Figure 3: Beam sizes.

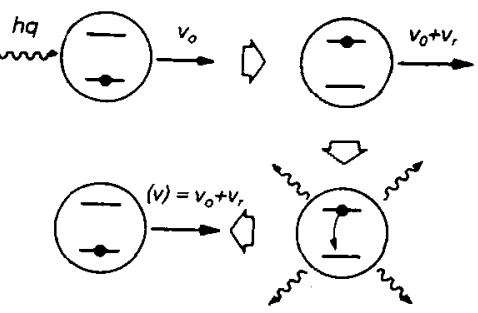

Sketch showing absorption and isotropic emission of a photon. resulting in momentum transfer in the direction of the incoming photon.

Figure 4: Laser cooling idea.

the straight sections momentum is transferred from a running light field to the circulating particles by absorption of photons. This momentum is later redistributed by spontaneous emission processes. Repeated scattering processes transfer momentum to the ions as a function of particle velocity. Close to a resonance between the laser field and the transition frequency for the ion/atom, acceleration rates as high as $100 \mathrm{keV} / \mathrm{sec}$ can be obtained.

Two lasers are used for the experiments, one beam copropagating with stored ions, the other counter propagating the ions. The absorption of the laser beams are monitored by measuring the emitted fluorescence light by a photomultiplier. Figure 5 shows the results from cooling of a $100 \mathrm{keV}$ metastable beam stored in ASTRID.

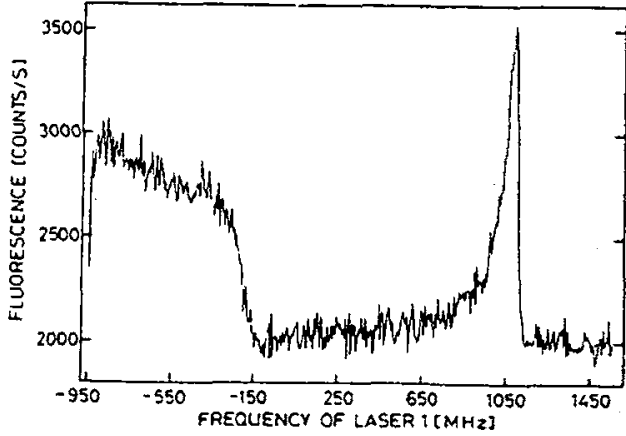

Fig. 5: Fluorescence vs. frequency of the swept laser. The horizontal scale is the difference between the laser frequency and the resonance frequency in the $100-\mathrm{keV}$ particle frame. In this frame the fixed laser (copropagating) is detuned $1100 \mathrm{MHz}$ to the red.

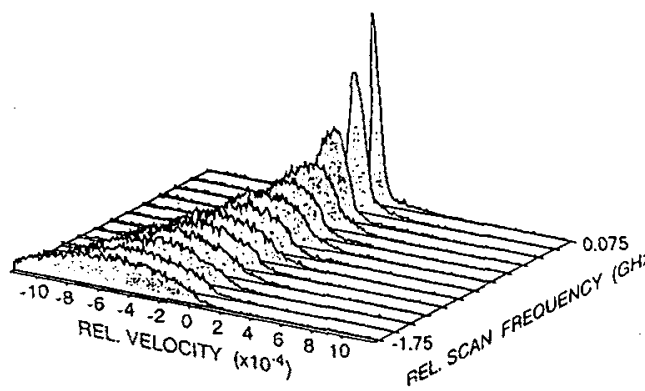

Fig. 6: Time development of the velocity distribution of a RF-bunched ${ }^{24} \mathrm{Mg}^{+}$stored beam using laser cooling.

At injection, the longitudinal $T_{\mid}$and transversal $\left(T_{\perp}\right)$ temperatures were $100^{\circ} \mathrm{mK}$ and $1000^{\circ} \mathrm{K}$, respectively (see Ref. 4 for details). Later experiments have shown that the prime reason for the "edge" effect was a higher-order vertical resonance in the beam which showed up around $1 \mathrm{sec}$ after the injection and caused a substantial loss of particles. At a slightly different tune 
the "edge" effect disappeared but the final cooling temperature was considerably higher $\left(200^{\circ} \mathrm{mK}\right)$.

A new ion $\left({ }^{24} \mathrm{Mg}^{+}\right)$has recently been used for laser cooling because here a closed transition from the ground state is available instead of the small fraction of metastable ions in the ${ }^{7} \mathrm{Li}^{+}$case. When the ${ }^{24} \mathrm{Mg}^{+}$is stored and $\mathrm{RF}$ bunched, the ions oscillate around the synchrotron energy. The amplitude of these oscillations can be strongly damped by the laser, as is shown in Fig. 6. This technique leads to a steady-state cold-stored beam using only one laser.

Equipment for electron cooling is also installed in one of the straight sections. Most ion velocities in ASTRID are small $(\beta \leq 0.1)$ so that the electron energy for the cooler can be kept below $3 \mathrm{keV}$. The low power levels associated with these energies mean that a classical electron gun of the Pierce type can be used. The focusing action of the anode aperture has been circumvented by placing a grid in the aperture. The electron cooler has until spring 1992 been installed in one of the tandem-beams for merged ion-electron beam experiments - like dielectronic recombination (DR) investigations. In Table 3 are given the parameters for the electron cooler.

\begin{tabular}{||l|l|}
\hline $\mathrm{e}^{-}$-beam diameter & $1.5 \mathrm{~cm}$ \\
\hline $\mathrm{e}^{-}$-energy & $50 \mathrm{eV}$ to $3000 \mathrm{eV}$ \\
\hline Maximum solenoid field & $300 \mathrm{Gauss}$ \\
\hline Interaction length & $80 \mathrm{~cm}$ \\
\hline Typical e current & $20 \mathrm{~mA}$ \\
\hline $\mathrm{e}^{-}$temperatures & $k T_{\perp}=0.15 \mathrm{eV}$ \\
& $k T_{1}=5.10^{-4} \mathrm{eV}$ \\
\hline
\end{tabular}

Table 3: Electron cooler parameters.

\begin{tabular}{|c|}
\hline $\begin{array}{l}\text { Positive ions: } \\
\mathrm{H}_{2}^{+}, \mathrm{D}^{+},{ }^{4} \mathrm{He}^{+},{ }^{6} \mathrm{Li}^{+},{ }^{7} \mathrm{Li}^{+}, \\
{ }^{9} \mathrm{Be}^{+},{ }^{16} \mathrm{O}^{+},{ }^{20} \mathrm{Ne}^{+},{ }^{24} \mathrm{Mg}^{+}, \\
{ }^{40} \mathrm{Ar}^{++},{ }^{151} \mathrm{Eu}^{+},{ }^{166} \mathrm{Er}^{+}, \\
{ }^{13} \mathrm{CO}^{+},{ }^{13} \mathrm{CO}^{++}\end{array}$ \\
\hline $\begin{array}{l}\text { Pasitive cluster lons: } \\
{ }^{12} \mathrm{C}_{60}^{+},{ }^{12} \mathrm{C}_{70}^{+}\end{array}$ \\
\hline $\begin{array}{l}\text { Negative ions: } \\
\mathrm{D}^{-},{ }^{3} \mathrm{He}^{-},{ }^{4} \mathrm{He}^{-},{ }^{4} \mathrm{He}_{2},{ }^{9} \mathrm{Be}- \\
{ }^{12} \mathrm{C}^{-},{ }^{16} \mathrm{O}^{-},{ }^{19} \mathrm{~F}^{4},{ }^{40} \mathrm{Ca}^{-} \\
{ }^{56} \mathrm{Fe}^{-}, \mathrm{OH}^{-}\end{array}$ \\
\hline $\begin{array}{l}\text { Negative cluster ions: } \\
{ }^{12} \mathrm{C}_{60}{ }^{12} \mathrm{C}_{70},{ }^{12} \mathrm{C}_{14}(n=1 . .14) \\
{ }^{27} \mathrm{Al}_{\mathrm{n}}(n=1 . .14),{ }^{29} \mathrm{Al}_{12} \mathrm{~B}^{-}\end{array}$ \\
\hline
\end{tabular}

Table 4: Ions stored in ASTRID.

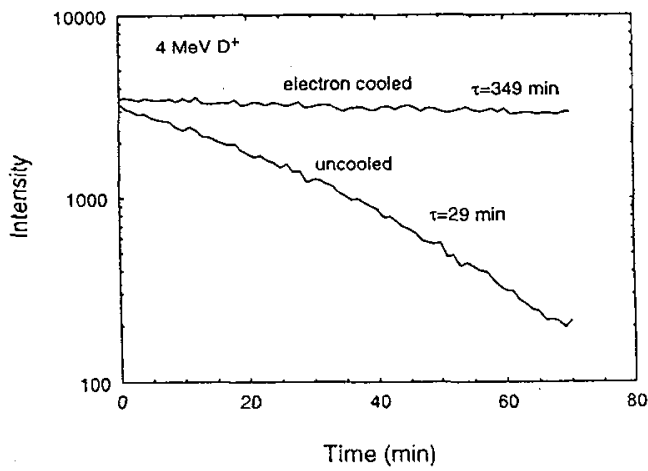

Figure 7: Heavy ion storage in ASTRID.

In a recent experiment, the hydrogen isotope $\mathrm{D}^{+}$was injected at $150 \mathrm{keV}$ and accelerated to $4 \mathrm{MeV}$ by the RF system. Figure 7 displays lifetime curves with ( $\tau=349 \mathrm{~min}$ ) and without $(\tau=29 \mathrm{~min})$ electron cooling - a factor of 12 increase in lifetime. 


\section{Ion storage}

Storage rings have for a long time been very important experimental tools in particles physics and for production of SR. Recently, however, it has turned out that storage rings are unique instruments in atomic physics research as well. Heavy ions (positive/negative) can be stored for several seconds to allow for long-rainge observation of atomic lifetimes in the range of $\sim 10 \mu \mathrm{s}$ to $\sim 100 \mathrm{~ms}-$ a time region, which is almost inaccessible through normal beam technique.

Measurements of structural/dynamical properties of weakly bound negative-ion systems provide an excellent test of calculations on many-body systems and electron correlation effects.

Ion storage was started in the spring 1990 . Since then, a large number of positive and negative ions have been stored. Ion species and clusters, which never were thought of during the design studies, have been stored. Until now, more than 30 ions and clusters of both polarities and with masses from 1 to $840 \mathrm{amu}$ haven been stored at energies ranging from 6 $\mathrm{keV}$ to $6 \mathrm{MeV}$. The ion types stored in ASTRID are shown in Table 4.

A new detector facility is constructed for the next ion period. The facility is installed in the corner behind the electron cooler using the $45^{\circ}$ dipole as analyzing magnet. Here it is possible to analyze charge and mass of fragments/ions/clusters from ion collisions with electrons and photons. For research programs, see Refs. 5, 6 and 7.

\section{The synchrotron radiation facility}

The design values for ASTRID operating as a SR source are shown in Table 5. while in Fig. 8 a comparison between radiation spectra from ASTRID and other SR facilities are depicted.

\begin{tabular}{|l|l|}
\hline Inspection energy & $100 \mathrm{MeV}$ \\
\hline Nominal current & $200 \mathrm{~mA}$ \\
\hline Electron energy & $580 \mathrm{MeV}$ \\
\hline Horizontal emittance & $0.17 \mathrm{~mm} \mathrm{mrad}$ \\
\hline Critical avarge wave length & $330 \mathrm{eV}, 37 \AA$ \\
\hline Energy loss/turn & $7.1 \mathrm{keV}$ \\
\hline Beam lifetimes & 24 hours \\
\hline Number of bunches & 14 \\
\hline RF frequency, Voltage & $104.9 \mathrm{MHz}, 25 \mathrm{KV}$ \\
\hline
\end{tabular}

Table 5: SR parameters

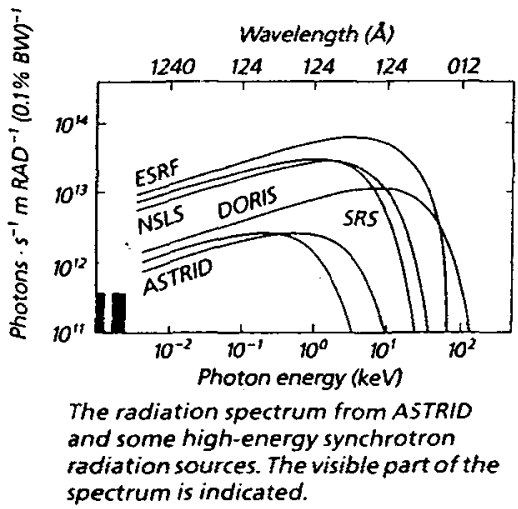

Figure 8.

It can in fact be shown that the machine energy and beam emittance of ASTRID are very well matched to provide an optimum undulator source (10-40 eV) for solid state and atomic phsyics. This is because the quality of the undulator is related to the $\mathbf{K}$-dependent fluc period in the device divided by the period itself. Normally, $\mathrm{K}$ is restricted to around 3 due to the undesirable "beta beating" at higher fields.

From this it is seen that ASTRID compares quite well in the XUV/VUV region. In Table 6 is given the RMS beam size and divergence in the middle of the straight section (for insertion devices) at the entrance and in the middle of a $90^{\circ}$ dipole. 
Until now, the following three SR beamlines are constructed, i.e. a) a dedicated beamline for imaging x-ray microscopy, b) a Zeiss (SX-700) plane grating monochromator

\begin{tabular}{||l|c|c|c||}
\hline & $\begin{array}{c}\text { Middle of straight } \\
\text { section }\end{array}$ & $\begin{array}{c}\text { Dipole } \\
\text { entrance }\end{array}$ & $\begin{array}{c}\text { Dipole } \\
\text { exit }\end{array}$ \\
\hline \hline$\sigma_{\mathrm{x}}(\mathrm{mm})$ & 1.54 & 0.44 & 0.50 \\
\hline$\sigma_{\mathrm{y}}(\mathrm{mm})$ & 0.21 & 0.29 & 0.06 \\
\hline$\sigma_{\mathrm{x}}^{\prime}(\mathrm{mrad})$ & 0.10 & 0.36 & 0.32 \\
\hline$\sigma_{\mathrm{y}}^{\prime}(\mathrm{mrad})$ & 0.08 & 0.06 & 0.27 \\
\hline
\end{tabular}

Table 6: ASTRID beam characteristics for the electron case.

followed by a complete UHV system for surface physics, and c) a new high resolution SGM $(\triangle \mathrm{E}: 30 \mathrm{eV}-600 \mathrm{eV})$ for atomic physics.

For SR, an electron current of more than $200 \mathrm{~mA}$ (design value) is routinely stored at the maximum energy of $580 \mathrm{MeV}$. The lifetime of the stored beam is 6 hours at $200 \mathrm{~mA}$ and 14 hours at $120 \mathrm{~mA}$, as can be seen from Fig. 9 .

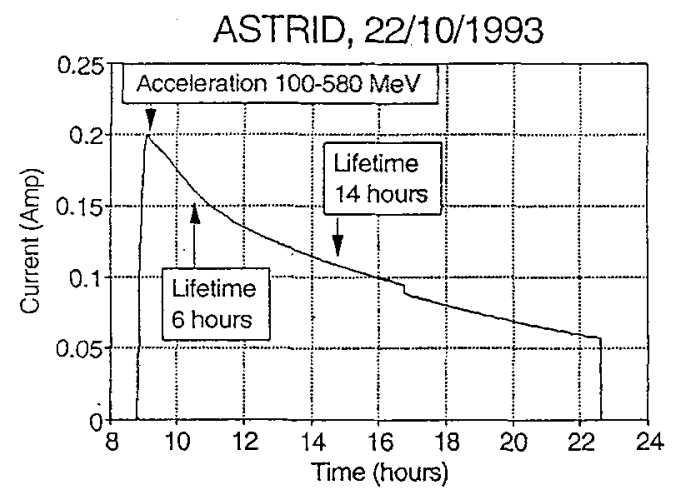

Fig. 9: Lifetime of stored electrons.

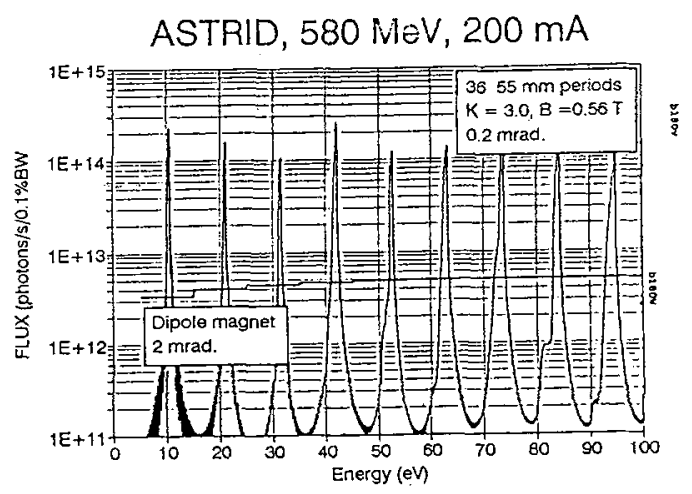

Figure 10: Undulator spectrum.

To increase the SR-flux, two undulators are under construction, i.e. a micropole undulator with minimum gap of $1 \mathrm{~mm}$ will be installed between the corner dipoles, where the beam cross section is very small. The device has 15 periods of $(6 \mathrm{~mm}$ length) permanent magnets $(\mathrm{SmCo}(2: 17))$. The material has been tested concerning out-gassing and has been found fully compatible to ASTRID-vacuum. The radiation flux is more than 10 times higher than that from a dipole in the water window $(0.28$ to $0.54 \mathrm{keV})$, and will be used for $\mathrm{x}$-ray microscopy. A standard VUV undulaton with a spectrum as shown in Fig. 10 is under construction.

In order of increasing the number of straight sections in ASTRID, a triangular addition is proposed (as indicated in Fig. 1). Two $45^{\circ}$ skew sections can be added to the old ring. The $90^{\circ}$ bending at the top will be performed by two $45^{\circ}$ superconducting magnets. Hereby two new straight sections with at least $2 \mathrm{~m}$ free space in each will be obtained for insertion devices. Next, the superconducting magnets (6-7 Tesla) act as wigglers to increase the characteristic energy of SR to $2.5 \mathrm{keV}$. A new laboratory space $\left(1500 \mathrm{~m}^{2}\right)$, surrounding the existing facility, has already been approved. 


\section{Conclusion}

The present description of ASTRID shows that it is possible to construct a lattice which fulfills the requirements to heavy ion storage and at the same time compares well with other SR sources in the soft $x$-ray region. Such a facility can serve a broad scientific society in physics, chemistry, biology, and materials science, and can be used as a home-laboratory for high energy physics and astrophysics.

\section{References}

[1] S.P. Møller in 14th Biennial Particle Accelerator Conference, San Francisco, May 1991 (Ed.: K. Berkner).

[2] E. Uggerhøj: ASTRID - A dual purpose storage ring for ions and electrons in Proceedings of the International Conference on Synchrotron Radiation Sources, Indore, India, February 3-6 1992. Ed.: S.S. Ramamurthi.

[3] M. Eriksson, Nucl.Inst.Methods A 261 (1987) 39.

[4] J.S. Hangst, M. Kristensen, J.S. Nielsen, O. Poulsen, J.P. Schiffer, and P. Shi, Phys.Rev.Lett. 67 (1991) 1238.

[5] L.H. Andersen, Comments At.Mol.Phys. 27 (1991) 25.

[6] T. Andersen et al., Phys.Rev. A 47 (1993) 890.

[7] L.H. Andersen et al., Chem.Phys.Lett. 217 (1994) 204. 